HEALTH SCIENCES

\title{
Longitudinal study of the sympathovagal balance in women submitted to bariatric surgery
}

\author{
CRISTINA M.S. LUCAS, DIVANEI ZANIQUELI, RAFAEL O. ALVIM, GUSTAVO P.S. \\ MIGUEL \& JOSÉ GERALDO MILL
}

\begin{abstract}
Studies have shown improvement of the cardiac autonomic balance in postbariatric patients. Most of these studies included patients using drugs interfering in the autonomic nervous system. This study assessed the time course of changes in the sympathovagal balance after bariatric surgery (Roux-en-Y gastric bypass) in 26 women free from drugs. A 10-min electrocardiographic recording was obtained at baseline and at 3 and 6 months after surgery. Temporal and spectral domains of heart rate variability were analysed. The time domain components of cardiac vagal modulation increased progressively after surgery. In the frequency domain, high frequency power increased from 24.9 at baseline (18.0 to 46.3 ) to 44.5 at 3 months (23.4 to 65.6), and 54.1 at 6 months after surgery (37.6 to 64.0) (median and IQR in normalized units). Low frequency spectral power decreased from 56.2 at baseline (39.6 to 74.4) to 36.8 at 6 months after surgery (24.9 to 53.9) $(\mathrm{P}=0.036)$. Low frequency/high frequency ratio decreased from 2.3 at baseline (1.0 to 4.2$)$ to 0.8 at 6 months after surgery ( 0.4 to 1.3$)(P=0.038)$. Progressive shift towards predominance of vagal tonus was detected in the follow-up. Most of the patients recovered low frequency/high frequency at 6 months after surgery.
\end{abstract}

Key words: Bariatric surgery, autonomic control, heart rate variability, vagus outflow.

\section{INTRODUCTION}

Obesity is a complex disease with an increasing incidence worldwide (Rashid et al. 2003, Flegal et al. 2015). Strong evidence based on epidemiological and clinical studies have shown that obesity is an independent risk factor for the development of cardiovascular diseases, type 2 diabetes mellitus and general mortality (Duflou et al. 1995, Calle et al. 1999). The degree of risk increases exponentially in presence of morbid obesity, that is, those individuals with a body mass index $\geq 40 \mathrm{~kg} / \mathrm{m}^{2}$ (Hubert et al.1983, Flegal et al. 2014). One study followed 200 morbidly obese men for a mean period of 7.5 years and a 12 -fold and 6 -fold mortality as compared with a controlled lean group was observed for the age groups of 25-34 years and 35-44 years, respectively (Drenick et al. 1980). These results indicate that severely obese patients, mainly among the youngest, demand specific strategies for treatment. In addition, it has been shown that cardiovascular diseases, usually associated to type 2 diabetes mellitus, are the most frequent complication observed in morbidly obese patients leading to increasing mortality due to coronary artery disease and sudden death (Duflou et al. 1995, Manson et al. 1995, Rashid et al. 2003).

Data from animal and human studies have demonstrated the occurrence of sympathetic overactivity in obese patients, predisposing to the development of hypertension and other complications derived from increasing 
oxygen consumption by the myocardium, such as ventricular arrhythmias and sudden death (Plourde et al. 2014). Clinical signs of this sympathoexcitation encompass elevated plasma noradrenaline levels, increased activity in the sympathetic nerves directed to skeletal muscles and increased urinary excretion of catecholamine metabolites, even in absence of hypertension (Grassi et al. 1995, Aronne et al. 1997, Laederach-Hofmann et al. 2000, Straznicky et al. 2008).

In the last three decades, several surgical procedures have been proposed to induce a rapid and permanent reduction of body weight. Vertical banded gastroplasty and gastric bypass procedures both limit food intake by accelerating satiety (Le Roux et al. 2007). Several studies have shown improvement of the autonomic balance in patients after bariatric surgery (Nault et al. 2007, Pontiroli et al. 2013). However, these studies included patients also presenting several co-morbidities and in use of several drugs interfering with the autonomic nervous system (Patel 2015), most of them used to control blood pressure.

Analysis of heart rate variability (HRV) has been increasingly used to assess the autonomic modulation directed to the cardiovascular system (Task Force of The European Society of Cardiology and The North American Society of Pacing and Electrosphysiology 1996). Therefore, this study sought to assess the time course of changes in the sympathovagal balance after bariatric surgery in obese women free from the influence of drugs interfering in the autonomic modulation of heartbeats.

\section{MATERIALS AND METHODS}

\section{Study population}

The study involved obese patients (BMI $\geq 35 \mathrm{~kg} /$ $\mathrm{m}^{2}$ ) aged 20-70 years recruited in the Service of Bariatric Surgery of the University Hospital, Vitória, ES, Brazil. From March to November/2015, 54 obese patients selected to undergo bariatric surgery accepted the invitation to take part in the study. From those, 13 were not included in the present analysis because they were using beta blockers or calcium channel blockers or sympathetic agonists before the surgery. Others 13 did not complete all exams in the follow up period ( 3 and 6 months). After these exclusions, only two men remained in the databases. Therefore, the present analysis was conducted with data from 26 female patients that attended to all clinical visits in the follow up.

Before bariatric surgery, patients were informed about potential risks and benefits from the surgery and about additional clinical exams to be done before surgery and in the follow up. Baseline exams were carried out as close as possible of the surgical procedure (in general within the week before). Presence of co-morbidities at baseline was obtained from the hospital records. Hypertension was present in $75 \%$ and type 2 diabetes mellitus in $29 \%$ of the sample previously to bariatric surgery. However, all patients had their blood pressure under control (<140/90 mmHg) with diuretics, ACE inhibitors, and AT1 receptor antagonist. All diabetic patients at baseline were under use of oral anti-diabetic drugs.

Surgery was scheduled only after controlling blood pressure (systolic/diastolic blood pressure $<140 / 90 \mathrm{mmHg}$ ) and fasting glucose ( $\leq 125 \mathrm{mg} /$ $\mathrm{dL}$ ). All patients included in this protocol were submitted to the Roux-en-Y gastric bypass (RYGB) by laparoscopy, a bariatric procedure recognized for inducing an important and longlasting body weight loss (Le Roux et al. 2007).

After surgery, all patients followed the standard protocol of medical visits programmed by assistant doctors, including all drug prescription. Patients gave written informed 
consent before participating. This study was approved by the Ethics Committee of the hospital (Number 04159312.6.0000.5071, 01/06/2012).

\section{Clinical examination}

All patients attended the Cardiovascular Investigation Clinic, located at the University Hospital. The same exams, performed by the same investigator, were conducted at baseline and at 3 and 6 months after bariatric surgery.

Body weight was obtained to the nearest $0.05 \mathrm{~kg}$ with a calibrated electronic scale (Toledo, Brazil) with barefoot individuals using only underclothes. Height was obtained to the nearest $0.1 \mathrm{~cm}$ with a wall-mounted scale (Seca Stadiometer - Seca GmBH \& Co, Hamburg, Germany). Percent body fat, fat mass and fat free masswere obtained by multi-frequency bioelectrical impedance analysis (MF-BIA8, InBody 230, Bioespace, South Korea). Body mass index (BMI) was calculated as the ratio between weight and the squared height $\left(\mathrm{Kg} / \mathrm{m}^{2}\right)$.

Systolic (SBP) and diastolic blood pressure (DBP) were measured with a validated oscillometric device (Omron 765-CP Intellisense, Japan) following standard techniques (Mill et al. 2013). After bladder emptying, the participant remained seated for at least 5 minutes in a quiet and temperature controlled room $\left(22-24^{\circ} \mathrm{C}\right)$. Cuffsize was appropriate to the arm circumference, according to the manufacturer instructions. Three consecutive readings with 1-2 minute intervals were obtained and the clinic SBP and DBP were obtained by the arithmetic mean of the last two readings.

A continuous 10-min electrocardiographic (ECG) recording was obtained with the individuals in a supine position without external stimulation and under normal breathing. The ECG recording was obtained with a digital device (Micromed, Brazil) at a sampling rate of $1 \mathrm{KHz}$. A dedicated software (Wincardio 4.4a,
Micromed, Brazil) generated the series of beatto-beat R-R intervals (generally D-II lead) to provide heart rate variability (HRV) analysis. Detailed information on the R-R series filtering and processing were published elsewhere (Dantas et al. 2010, 2012). Briefly, HRV analysis was carried out in time and frequency domains using a Matlab-customized software. The R-R series were automatically processed to remove artifacts and ectopic beats, which were replaced by linear interpolation. Criteria used to select the 5 min interval for HRV analysis were previously published (Dantas et al. 2018). Time domain components included the average of all normalto-normal intervals (NN), the variance of all NN intervals (variance of NN), standard deviation of all NN intervals (SDNN), the number of NN intervals differing more than $50 \mathrm{~ms}$ (NN50), the percentage of two NN intervals differing more than 50ms (pNN50), and the square root of the mean of the sum of the squares of differences between adjacent NN intervals (rMSSD). For the power spectral analysis, the R-R series were processed by the autoregressive method (model of order 16) to identify the three main components of the periodic fluctuations of heart beats: the very low frequency (VLF; 0-0.04 $\mathrm{Hz}$ ), low frequency (LF: 0.04-0.15 Hz), and the high frequency (HF: $0.15-0.40 \mathrm{~Hz}$ ) bands of the overall spectrum. Given that short term ECG recordings are inappropriate to investigate the VLF band, we submitted to analytic procedures only the LF and HF components of spectrum given in normalized units (nu). Normalization consisted of dividing the power of each component by total power minus power of VLF component. LF/ $\mathrm{HF}$ ratio was obtained dividing the low frequency component by high frequency component and was used to indicate sympathovagal balance (Task Force of The European Society of Cardiology and The North American Society of Pacing and Electrophysiology 1996). 


\section{Data analysis}

All data were tested for normal distribution by the Kolmogorov Smirnov test. Data with normal distribution were analyzed with oneway repeated-measures ANOVA, and in case of significant $F$ test, Tukey post-hoc test was conducted. Nonparametric Kruskal-Wallis by ranks test was performed for those data withnon-normal distribution, and in case of significant $\mathrm{H}$ test, Dunn's multiple comparisons test was conducted as post-hoc. All statistical procedures were carried out with GraphPad Prism 6.0 (GraphPad Software, Inc., CA, USA). P< 0.05 (two-tailed) was considered statistically significant.

\section{RESULTS}

Baseline age was $42.6 \pm 11.6$ years. The general characteristics of the patients at baseline and at 3 and 6 months after surgery are shown in Table I. As expected, a significant body weight loss occurred following surgery. The greater weight loss (16.8\%) was observed at 3 months after surgery. Relative weight loss was attenuated (additional 10.4\%) thereafter. The fat reduction was not uniform according to the body region, with a greater fat reduction in the upper extremity (55.6\%) compared to trunk (33.8\%) and lower extremity (34.9\%), 6 months after surgery. No adverse outcome was reported by the patients within the follow-up period.

The time course of changes in the time domain and spectral components of HRV with the volunteers in the supine position is shown in Table II. A progressive decrease in the mean heart rate obtained from the 10 min ECG recording was observed. On the other hand, a significant change in the time domain components of HRV was observed only later. A 47\% increase in rMSSD
$(P<0.01)$ and a $285 \%$ increase in pNN50 $(P<0.01)$ was observed at 6 months after bariatric surgery.

The time course of changes in the spectral components of HRV is shown in Figure 1. LF (nu) spectral power (Fig. 1a) decreased from 56.2 (39.6 to 74.4 ) at baseline to 36.8 (24.9 to 53.9) at 6 months after surgery $(P=0.036)$. Differently, $\mathrm{HF}$ (nu) (Fig. 1b) increased progressively from 24.9 (18.0 to 46.3 ) at baseline to 44.5 (23.4 to 65.6) at 3 months and to 54.1 (37.6 to 64.0) at 6 months after surgery. LF/HF ratio in turn (Fig. 1C) decreased from 2.3 (1.0 to 4.2) at baseline to 0.8 (0.4 to 1.3$)$ at 6 months after surgery $(P=0.038)$.

\section{DISCUSSION}

The main findings of this study were the improvement of the vagal cardiac control within the three months, as well as the recovery of the autonomic balance at six months of the postsurgical period.

The data obtained in this study confirmed previous observations regarding the efficacy of the bariatric surgery as a procedure to obtain rapid weight loss, a goal obtained particularly when using the Roux-en-Y bypass procedure (Le Roux et al. 2007, Li et al. 2016). The long-lasting maintenance of the body weight has been questioned in some studies (Shah et al. 2006). Our data suggest that the fat loss seems not to be uniform in the different body segments since the relative fat loss localized in the upper extremity was greater than in the central body (trunk), suggesting that central fat is more resistant to the reduced caloric intake after surgery.

It is noteworthy that the reduction of body fat occurred simultaneously to a rearrangement of the autonomic balance to the heart, from a relatively predominant sympathetic pattern (lower pNN50 and rMSSD values and higher LF/ 
a

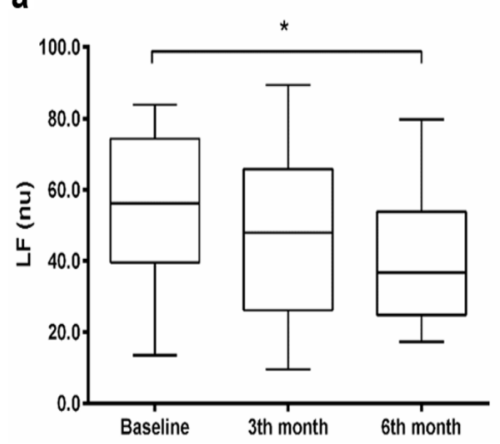

b

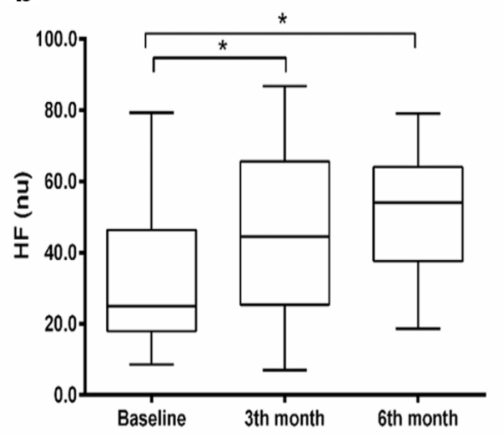

C

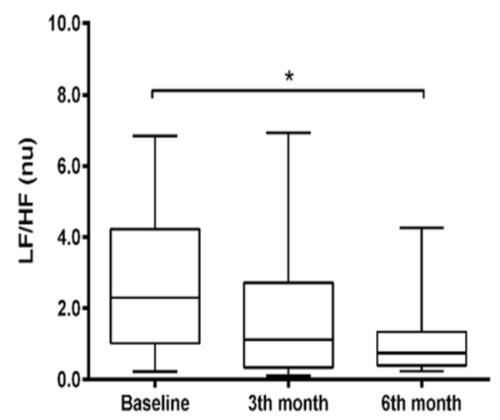

Figure 1. Spectral components of HRV analysis at baseline and at follow up after bariatric surgery. a) LF spectral power in normalized units, b) HF spectral power in normalized units, c) LF/HF ratio. Boxes are median, 25th and 75th percentiles, and whyskers indicate 1st and 99th percentiles. *Significantly different from baseline values ( $P<$ 0.05). Kruskal Wallis with Dunn's post-hoc test.

Table I. Time course of changes in heart rate and time-domain components of heart rate variability.

\begin{tabular}{|c|c|c|c|}
\hline & Baseline & $\mathbf{3}$ months & $\mathbf{6}$ months \\
\hline Minimum HR (bpm) & $63 \pm 12$ & $55 \pm 13^{\star}$ & $52 \pm 8^{\star}$ \\
\hline Maximum HR (bpm) & $86 \pm 13$ & $80 \pm 14^{\star}$ & $76 \pm 12^{\star}$ \\
\hline Mean HR (bpm) & $73 \pm 13$ & $67 \pm 14^{\star}$ & $62 \pm 9^{\star}$ \\
\hline R-R (ms) & $850 \pm 152$ & $933 \pm 171$ & $985 \pm 143^{\star}$ \\
\hline R-R variance (ms $\left.{ }^{2}\right)$ & $1261(455-2726)$ & $3336(1030-5604)$ & $2709(1696-5047)$ \\
\hline SDNN (ms) & $35.5(21.3-52.2)$ & $57.7(32.1-74.8)$ & $52.0(41.2-71.0)$ \\
\hline rMSSD (ms) & $22.2(15.5-35.1)$ & $31.0(17.4-63.6)$ & $32.6(28.1-63.2)^{\star}$ \\
\hline NN50 (absolute value) & $15(03-100)$ & $41(07-273)$ & $64(28-242)^{\star}$ \\
\hline pNN50 (\%) & $2.3(0.3-13.6)$ & $5.9(1.5-45.8)$ & $10.4(5.7-43.0)^{\star}$ \\
\hline
\end{tabular}

HR heart rate, SDNN standard deviation of all NN intervals, rMSSD square root of the mean of the sum of the squares of differences between adjacent NN intervals, NN50 number of NN intervals differing more than 50ms, pNN50 percentage of two NN intervals differing more than $50 \mathrm{~ms}$. Values are mean \pm standard deviation or median (interquartile interval). *Different from baseline values $(P<0.05)$. Repeated measures ANOVA with post-hoc Tukey or Kruskal Wallis with Dunn's post-hoc test.

HF ratio) before surgery, to a more balanced sympathetic/parasympathetic pattern characterized by the decrease of LF/HF ratio in the postsurgical period. Recently, our group published reference values for HRV derived from a large cohort of healthy adults (Dantas et al. 2018). Considering rMSSD and pNN50, two parameters related to vagal modulation of HRV, our data showed normalization of its values at 6 months of the follow up period. Similar normalization was observed in relation to LF/HF.
However, the recovery of the normal autonomic balance to the heart was not timely related to the weight loss, because as shown in Fig.1c decreased LF/HF ratio was only detectable 6 months after surgery. Our data also suggest that the recovery of the normal pattern of sympathetic/ parasympathetic balance seems not to be uniform in all patients since the recovery of the temporal and spectral parameters, suggesting increase of parasympathetic modulation on the

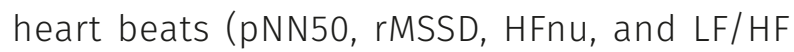


Table II. Anthropometric and hemodynamic data at baseline and at follow up after bariatric surgery.

\begin{tabular}{|c|c|c|c|}
\hline & Baseline & 3 months & 6 months \\
\hline Weight (kg) & $116.5 \pm 18.7$ & $97.0 \pm 16.0^{*}$ & $87.2 \pm 15.4^{\star \#}$ \\
\hline BMI $\left(\mathrm{kg} / \mathrm{m}^{2}\right)$ & $44.1 \pm 6.3$ & $37.2 \pm 6.6^{\star}$ & $33.0 \pm 5.4^{*}$ \\
\hline Fat mass (\%) & $52.7 \pm 6.1$ & $47.3 \pm 6.4^{*}$ & $41.5 \pm 7.0^{* \#}$ \\
\hline Fat mass (kg) & $60.2 \pm 12.6$ & $45.8 \pm 11.3^{*}$ & $36.3 \pm 11.0^{\star \#}$ \\
\hline UB fat mass (kg) & $15.4 \pm 5.8$ & $10.1 \pm 3.8^{*}$ & $7.0 \pm 3.6^{\star \#}$ \\
\hline LB fat mass (kg) & $17.4 \pm 4.3$ & $14.2 \pm 3.9^{*}$ & $9.9 \pm 3.8^{\star \#}$ \\
\hline Trunk fat mass (kg) & $26.2 \pm 3.4$ & $20.9 \pm 4.3^{*}$ & $16.9 \pm 4.9^{\star \#}$ \\
\hline FFM (kg) & $30.2 \pm 7.0$ & $27.4 \pm 5.7^{\star}$ & $27.9 \pm 5.0^{*}$ \\
\hline $\mathrm{SBP}(\mathrm{mmHg})$ & $120 \pm 15$ & $117 \pm 11^{*}$ & $115 \pm 12^{*}$ \\
\hline $\mathrm{DBP}(\mathrm{mmHg})$ & $79 \pm 10$ & $73 \pm 7^{*}$ & $70 \pm 7^{*}$ \\
\hline
\end{tabular}

BMI body mass index, UB upper body, LB lower body, FFM fat free mass, SBP systolic blood pressure, DBP diastolic blood pressure. Values are mean \pm standard deviation. *Different from baseline values, " Different from 3 months $(P<0.05)$. Repeated measures ANOVA with Tukey post-hoc test.

ratio), was only evident 6 months after surgery. Also, in some patients the sympathovagal balance remained unchanged after surgery, that is, the predominant sympathetic pattern remained unchanged despite the weight loss. We were unable to identify a common characteristic (presence of diabetes, for example) in this subgroup. A cohort containing a higher number of participants should be studied to investigate this finding.

Previous studies have shown that the autonomic imbalance associated with obesity is derived from an activation of the sympathetic system and such activation was more intense in presence of visceral in comparison with the subcutaneous fat accumulation and that leptin, an important hormone secreted by visceral adipocytes, would be associated to the sympathetic activation and obesity-induced hypertension (Alvarez et al. 2002, Mark 2013). Our data did not confirm this view because in our cohort we observed a predominant recovery of the parasympathetic indexes of HRV. However, it is important to consider HRV analysis is not a good tool to investigate sympathetic modulation, since the LF component depends on a complex interaction of sympathetic and parasympathetic discharge to the heart, partially modulated by the barorreflex (Task Force of The European Society of Cardiology and The North American Society of Pacing and Electrophysiology 1996, Guzzetti et al. 2002). Although data of normal values of HRV parameters are still scarce (Nunan et al. 2010, Dantas et al. 2018), we observed that most of the patients included in our study and examined 3 months after surgery showed temporal indexes of vagal modulation of heart beats close to those found in normal volunteers (Nunan et al. 2010, Mill et al. 2013). It is possible that the recovery of the autonomic balance may depend on a better baroreflex signaling, as previously shown in obese patients at 3 and 6 months after surgery (Kokkinos et al. 2013). We can speculate that the recovery of normal sympathetic/parasympathetic balance contributes to a better blood pressure control making possible to hypertensive obese patients recover normal blood pressure even after withdrawal of the antihypertensive medication. Notably, 21 out of 23 patients showed normal 
blood pressure values without antihypertensive drugs in the follow up period. However, given the high proportion of patients under hypertension treatment at baseline, it was difficult to correlate blood pressure changes with weight loss.

The sympathetic activation in obesity has been largely attributable to the high leptin levels. This hormone is able to directly stimulate the hypothalamic neurons involved in the sympathetic activation network (Varela \& Horvath 2015, do Carmo et al. 2016). A possible inhibition of vagal tone by leptin was also proposed (de Lartigue et al. 2012). Unfortunately, we did not measure leptin levels in our cohort. However, other studies have shown decreased serum leptin concentration after bariatric surgery (Siejka et al. 2013, Knuth et al. 2014). Moreover, two other additional hypotheses may be raised to explain the recovery of the sympathovagal balance after the bariatric surgery: a better control of diabetes and improvement of sleep obstructive apnea (SOA). Both conditions lead to an increase in the sympathetic drive to the cardiovascular system. Eight out of the 26 patients included in our study were under treatment for diabetes. The improvement of the autonomic balance in the post-surgical period, however, was similar in diabetic and non-diabetic patients (data not shown). In contrast, it has been recently reported that the bariatric surgery may be more effective in restoring the cardiac autonomic control in patients with type 2 diabetes as compared to those nondiabetic patients (Casellini et al. 2016). In relation to SOA, 18 out of the 26 patients reported the previous diagnosis of SOA at baseline and most of them reported improvement of sleep quality with weight loss. Indeed, a recent study has shown that the weight loss after bariatric surgery was more efficient to restore the sympathovagal balance in obese patients with SOA than the use of positive air flow devices (CPAP) (Bakker et al. 2014).
In conclusion, our study clearly showed improvement of the autonomic balance as assessed by HRV indexes directed to the heart after bariatric surgery in severely obese patients. Despite the limitation of using a small and non-randomized sample, unlike other studies, we included in this analysis only patients free from the influence of drugs interfering with the autonomic modulation of heart beats (mainly betablockers and central sympatholitics). Other studies have recommended the withdrawal of medication only one day before of ECG recording (Wu et al. 2015) what is insufficient to wash out most of the drugs used in the treatment of hypertension.

The findings of this study indicate that recovery of normal parasympathetic modulation may be a major contributor to normalization of cardiac autonomic balance. The recovery of the normal autonomic balance to the heart may contribute to improve reflex control of blood pressure and to normalize blood pressure levels in hypertensive obese individuals.

\section{Acknowledgments}

The authors would like to thank all volunteers and staff of University Hospital for helping in the recruitment and Coordenação de Aperfeiçoamento de Pessoal de Nivel Superior (CAPES) for financial support.

\section{REFERENCES}

ALVAREZ GE, BESKE SD, BALLARD TP \& DAVY KP. 2002. Sympathetic neural activation in visceral obesity. Circulation 106: 2533-2536.

ARONNE LJ, MACKINTOSH R, ROSEMBAUM M, LEIBEL RL \& HIRSCH J. 1997. Cardiac autonomic nervous system activity in obese and never-obese young men. Obes Res 5: 354-539.

BAKKER JP, CAMPANA LM, MONTESI SB, BALACHANDRAN J, DEYOUNG PN, SMALES E, PATEL SR \& MALHOTRA A. 2014. A pilot study investigating the effects of continuous positive airway pressure treatment and weight-loss surgery on autonomic activity in obese obstructive sleep apnea patients. J Electrocardiol 47: 364-373. 
CALLE EE, THUN MJ, PATRELLI JM, RODRIGUEZ C \& HEATH JR CW. 1999. Body mass index and mortality in a prospective cohort of US adults. N Engl J Med 341: 1097-1105.

CASELLINI CM, PARSON HK, HODGES K, EDWARDS JF, LIEB DC, WOHLGEMUTH SD \& VINIK AI. 2016. Bariatric surgery restores cardiac and sudomotor autonomic c-fiber dysfunction towards normal in obese subjects with type 2 diabetes. PLOS ONE 11(5): e0154211.

DANTAS EM, GONÇALVES CP, SILVA ABT, RODRIGUES SL, RAMOS MS, ANDREÃO RV, PIMENTEL EB, LUNZ W \& MILL GJ. 2010. Reproducibility of heart rate variability parameters measured in healthy subjects at rest and after a postural change maneuver. Braz J Med Biol Res 43: 982-988.

DANTAS EM, KEMP AH, ANDREÃO RV, DA SILVA VJD, BRUNONI AR, HOSHI RA, BENSENOR IM, LOTUFO PA, RIBEIRO ALP \& MILL JG. 2018. Reference values for short-term resting-state heart rate variability in healthy adults: Results from the Brazilian Longitudinal Study of Adult Health, ELSA-Brasil study. Psychophysiology 55: e13052.

DANTAS EM, SANT'ANNA ML, ANDREÃO RV, GONÇALVES CP, MORRA EA, BALDO MP, RODRIGUES SL \& MILL JG. 2012. Spectral analysis of heart rate variability with the autoregressive method: what model order to choose? Comput Biol Med 42: 164-170.

DE LARTIGUE G, BARBIER DE LA SERRE C, ESPERO E, LEE J \& RAYBOULD HE. 2012. Leptin resistance in vagal afferent neurons inhibits cholecystokinin signaling and satiation in diet induced obese rats. PLoS ONE 7: e32967.

DO CARMO JM, DA SILVA AA, WANG Z, FANG T, ABERDEIN N, RODRIGUEZ CE \& HALL JE. 2016. Obesity-induced hypertension: brain signaling pathways. Curr Hypertens Rep 18: 58.

DRENICK EJ, BALE GS, SELTZER F \& JOHNSON DG. 1980. Excessive mortality and causes of death in morbidly obese men. JAMA Cardiol 243: 443-445.

DUFLOU J, VIRMANI R, RABIN I, BURK A, FARB A \& SMIALEK J. 1995. Sudden death as a result of heart disease in morbid obesity. Am Heart J 130: 306-313.

FLEGAL KM, KIT BK \& GRAUBARD BI. 2014. Body mass index categories in observational studies of weight and risk of death. Am J Epidemiol 180: 288-296.

FLEGAL KM, PANAGIOTOU OA \& GRAUBARD BI. 2015. Estimating population attributable fractions to quantify the health burden of obesity. Ann Epidemiol 25: 201-207.

GRASSI G, SERAVALLE G, CATTANEO BM, BOLLA GB, LANFRANCHI A, COLOMBO M, GIANNATTASIO C, BRUNANI A, CAVAGNINI F \& MANCIA G. 1995. Sympathetic activation in obese normotensive subjects. Hypertension 25: 560-563.
GUZZETTI S, SPYROU N, ROSEN SD, MEZZETTI S, MARTINOLI E, FOALE RA \& CAMICI PG. 2002. Low frequency spectral component of heart rate variability and myocardial betaadrenoceptor density after acute myocardial infarction. Basic Res Cardiol 97: 97-104.

HUBERT HB, FEINLEIB M, MCNAMARA PM \& CASTELLI WP. 1983. Obesity as an independent risk factor for cardiovascular disease: a 26-year follow-up of participants in the Framingham Heart Study. Circulation 67: 968-976.

KNUTH ND, JOHANNSEN DL, TAMBOLI RA, MARKS-SHULMAN PA, HUIZENGA R, CHEN KY, ABUMRAD NN, RAVUSSIN E \& HALL KD. 2014. Metabolic adaptation following massive weight loss is related to the degree of energy imbalance and changes in circulating leptin. Obesity 22: 2563-2669.

KOKKINOS A ET AL. 2013. Improvement in cardiovascular indices after Roux-en-Y gastric bypass or Sleeve gastrectomy for morbid obesity. Obes Surg 23: 31-38.

LAEDERACH-HOFMANN K, MASSGAY L \& RUDELL H. 2000. Autonomic cardiovascular regulation in obesity. J Endocrinol Diabetes 164: 59-66.

LE ROUX CW ET AL. 2007. Gut hormones as mediators of appetite and weight loss after Roux-en-Y gastric bypass. Ann Surg Treat Res 30: 1199-1203.

LI J, LAI D \& WU D. 2016. Laparoscopic Roux-en-Y Gastric Bypass Versus Laparoscopic Sleeve Gastrectomy to Treat Morbid Obesity-Related Comorbidities: a Systematic Review and Meta-analysis. Obes Surg 26: 429-442.

MANSON JE, WILLETT WC, STAMPFER MJ, COLDITZ GA, HUNTER DJ, HANKINSON SE, HENNEKENS CH \& SPEIZER FE. 1995. Body weight and mortality among women. N Engl J Med 333: 677-685.

MARK AL. 2013. Selective leptin resistance revisited. Am J Physiol Regul Integr Comp Physiol 305: 566-581.

MILL JG ET AL. 2013. Medical assessments and measurements in ELSA-Brasil. Rev Saude Publica 2: $54-62$

NAULT I ET AL. 2007. Impact of bariatric surgery-induced weight loss on heart rate variability. Metabolism 56: 1425-1430.

NUNAN D, SANDERCOCK GR \& BRODIE DA. 2010. A quantitative systematic review of normal values for shortterm heart rate variability in healthy adults. Pacing Clin Electrophysiol 33: 1407-1417.

PATEL D. 2015. Pharmacotherapy for the management of obesity. Metabolism 64: 1376-1385. 
PLOURDE B, SARRAZIN JF, NAULT I \& POIRIER P. 2014. Sudden cardiac death and obesity. Expert Rev Cardiovasc Ther 12: 1099-1110.

PONTIROLI AE, MERLOTTI C, VERONELLI A \& LOMBARDI F. 2013. Effect of weight loss on sympatho-vagal balance in subjects with grade-3 obesity: restrictive surgery versus hypocaloric diet. Acta Diabetol 50: 843-850.

RASHID MN, FUENTES F, TOUCHON RC \& WEHNER PS. 2003. Obesity and the risk for cardiovascular diseases. Prev Cardiol 6: 42-47.

SHAH M, SIMHA V \& GARG A. 2006. Long-term impact of bariatric surgery on body weight, comorbidities, and nutritional status. J Clin Endocrinol Metab 91: 4223-4231.

SIEJKA A, JANKIEWICZ-WIKA J, KOŁOMECKI K, CYWIŃSKI J, PIESTRZENIEWICZ K, SWIĘTOSŁAWSKI J, STĘPIEŃ H \& KOMOROWSKI J. 2013. Long-term impact of vertical banded gastroplasty (VBG) on plasma concentration of leptin, soluble leptinreceptor, ghrelin, omentin-1, obestatin, and retinol binding protein 4 (RBP4) in patients with severe obesity. Cytokine 64: 490-493.

STRAZNICKY NE, EIKELIS N, LAMBERT EA \& ESLER MD. 2008. Mediators of sympathetic activation in metabolic syndrome obesity. Curr Hypertens Rep 10: 440-447.

TASK FORCE OF THE EUROPEAN SOCIETY OF CARDIOLOGY AND THE NORTH AMERICAN SOCIETY OF PACING AND ELECTROPHYSIOLOGY. 1996. Heart rate variability: standards of measurements, physiological interpretation and clinical use. Circulation 93: 1043-1065.

VARELA L \& HORVATH TL. 2015. A sympathetic view on fat by leptin. Cell 163: 26-27.

WU JM, YU HJ, LAI HS, YANG PJ, LIN MT \& LAI F. 2015. Improvement of heart rate variability after decreased insulin resistance after sleeve gastrectomy for morbidly obesity patients. Surg Obes Relat Dis 11: 557-563.

\section{How to cite}

LUCAS CMS, ZANIQUELI D, ALVIM RO, MIGUEL GPS \& MILL JG. 2020. Longitudinal study of the sympathovagal balance in women submitted to bariatric surgery. An Acad Bras Cienc 92: e20181184. DOI 10.1590/00013765202020181184.

Manuscript received on November 12, 2018;

accepted for publication on February 8, 2019

\section{CRISTINA M.S. LUCAS ${ }^{1}$}

https://orcid.org/0000-0001-5874-1133

\section{DIVANEI ZANIQUELI ${ }^{1}$}

https://orcid.org/0000-0002-6146-1658

\section{RAFAEL O. ALVIM ${ }^{2}$}

https://orcid.org/0000-0003-3150-4239

\section{GUSTAVO P.S. MIGUEL ${ }^{3}$}

https://orcid.org/0000-0003-3691-4093

\section{JOSÉ GERALDO MILL'}

https://orcid.org/0000-0002-0987-368X

${ }^{1}$ Programa de Pós-Graduação em Ciências Fisiológicas, Clínica de Investigação Cardiovascular, Universidade Federal do Espírito Santo, Av. Marechal Campos, 1468, Maruipe, 29047-105 Vitória, ES, Brazil

${ }^{2}$ Departamento de Ciências Fisiológicas, Instituto de Ciências Biológicas, Universidade Federal do Amazonas, Av. Gen. Rodrigo Octávio, 6200, Coroado, 69080-900 Manaus, AM, Brazil ${ }^{3}$ Departamento de Cirurgia, Hospital Universitário, Universidade Federal do Espírito Santo, Av. Marechal Campos, 1468, Maruipe, 29047-105 Vitória, ES, Brazil

\section{Correspondence to: Rafael de Oliveira Alvim}

E-mail:r.alvim@hotmail.com

\section{Author contributions}

CMSL: acquisition of data and drafting the manuscript, DZ and ROA: interpretation of data and drafting the manuscript, GPSM: acquisition and interpretation of data, and JGM: conception and final approval of the manuscript.

\section{(cc) BY}

